\title{
APOYO VIRTUAL EN LA EDUCACIÓN PRESENCIAL
}

\section{BLENDED LEARNING: IMPLEMENTACIÓN Y BENEFICIOS}

Nandy Rodríguez, MD*

a implementación escalonada y modular de la modalidad blended learning o apoyo virtual para la educación presencial a través de la elaboración de objetos virtuales para el aprendizaje, permite mayor eficiencia, eficacia y calidad del nivel de la enseñanza. Los beneficios para la institución, el docente y el estudiante son la optimización del tiempo, la facilitación de una forma diferente de enseñanza y la autonomía en el aprendizaje.

La educación presencial hasta ahora ha sido la modalidad conocida y aceptada por la comunidad en general. Con los desarrollos tecnológicos de la informática y la comunicación (TIC) aparecen nuevas herramientas que han ingresado en forma gradual en todas las áreas de nuestro quehacer diario, incluida el área de la educación.

Existen dos grandes métodos de enseñanza con el uso de novedades TIC. Uno es e-learning que se define como educación electrónica y consiste en el uso de TIC para la presentación de los recursos, evaluaciones y las tutorías, quiere decir que toda la actividad es virtual. El otro método es el b-learning, proviene del verbo inglés blend que traduce mezclar o combinar y consiste en el uso de TIC para la presentación de los recursos y evaluaciones, mientras las tutorías se realizan en forma presencial.

El reto es aprovechar las nuevas tecnologías y la web 2 (redes sociales y blogs) en beneficio de la educación presencial, lo cual redunda en eficiencia, eficacia y

* Coordinadora de telemedicina, Fundación Universitaria de Ciencias de la Salud. Bogotá DC. Colombia.

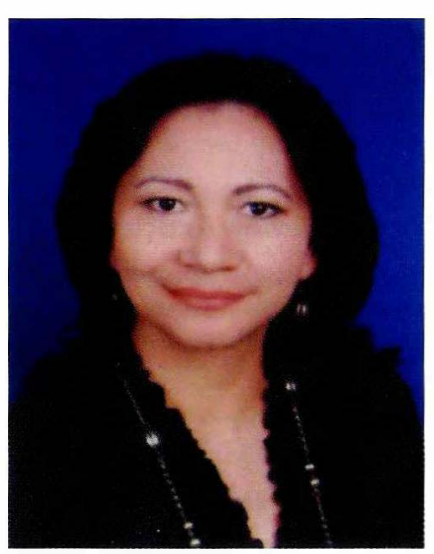

calidad en el ejercicio de la educación. Según Batolomé, 2004, estas herramientas se pueden integrar en una universidad radicional convirtiendo sus programas de pre y postgrado en cursos mixtos, semipresenciales o blended learning (b-learning), mientras que la modalidad virtual o e-learning está tomando mucha fuerza para los programas de educación continuada. Profundizaremos en la primera que corresponde al apoyo virtual a la educación presencial. Con este modelo se busca mejorar la calidad de la educación al ofrecer al estudiante un método diferente que lo apoye en la adquisición de conocimientos y competencias específicas. Se trabaja mediante objetos virtuales de aprendizaje (OVA) definidos como "pieza digital de material educativo, cuyos temas y contenidos pueden ser claramente identificables $y$ direccionables, y cuyo principal potencial es la reutilización dentro de distintos contextos aplicables a la educación virtual" (Ruiz, 2006).

Beneficios: los beneficios del apoyo virtual en la educación presencial se reflejan en los tres participantes: 
la institución, el docente y el estudiante. Para la primera radican en el adecuado aprovechamiento del tiempo de los otros dos así como de la infraestructura y el espacio. Para el docente en la facilidad de ofrecerle al estudiante una forma diferente de aprender a través de OVA. Para los alumnos a mi juicio los más importante son la disponibilidad y reutilización de los recursos, actividades y autoevaluaciones con libertad de tiempo y espacio a través de una interfase de multimedia, que les permite desarrollar su actividad de aprendizaje con autonomía (Canaves, 1998). Por último, beneficia a todos los participantes al permitir realizar evaluaciones documentadas y verificables de las actividades, con miras a desarrollar programas de mejora continua.

\section{Implementación}

Todainstución interesada en implementar la modalidad de $b$-learning debe trabajar en tres frentes: primero, desarrollar una estrategia institucional y utilizarla en forma gradual para no crear crisis en el desarrollo de los programas presenciales existentes. En nuestra institución se escogió una escalable y modular que permite una libertad controlada en el desarrollo de la modalidad, de manera que cada programa elabore mínimo dos OVA por año, y a su vez cada programa debe funcionar en forma modular imprimiendo la velocidad que desee para lograr en un tiempo corto su implementación. Se espera con esta estrategia en el término de tres años implementar el $80 \%$ de nuestros programas. El segundo aspecto se refiere a capacitar a su equipo de docentes en la utilización de las herramientas de multimedia y web 2 y en la creación de OVA. En la FUCS se dicta un curso presencial desde 2006 que no ha tenido el impacto esperado en la planta de docentes, en especial por la poca disponibilidad de tiempo. Por esta razón en febrero de 2010 se creó un curso virtual cíclico de capacitación para docentes el cual se está repitiendo cada dos meses. Nuestro objetivo es que en un período de un año debemos tener capacitado por lo menos al $30 \%$ de nuestros profesores y en dos años el $80 \%$. El tercer punto es desarrollar en el estudiante competencias comunicativas, las cuales son importantes para su vida futura, como son:

- Buscar y encon war información relevante en la red.

- Desarrollar criterios para valorar esa información y poseer indicadores de calidad.

- Aplicar lo anterior para la elaboración de nuevos conceptos y situaciones reales.

- Trabajar en equipo compartiendo y elaborando información.

- Decidir con base en informaciones contrastadas.

- Tomar las decisiones en grupo.

En resumen, estamos en un momento único en la educación, nuestro reto es ingresar a la modalidad $b$-learning o apoyo virtual para la eduacion presencial en forma escalonada y modular que facilite su implementación. La institucion debe tener conformada una oficina de coordinacion de teleducación y una unidad de ambientes virtuales que garantice la realizacion de OVA con estándares nacionales e internacionales. En conclusión y como se diria en otro contexto, solo falta el soplo divino que está en la motivacion interna del ser humano.

\section{Lecturas recomendadas}

Aprendizaje combinado o Blended Leaming. Wikilibro. 26 Jul 2009 http://es.wikibooks.org/wiki/Aprendizaje_combinado.

Bartolomé, A. (2004). Blended Learning. Conceptos básicos. Pixel-Bit . Revista Medios y Educacion. Mayo: $N^{\circ}$ 023. Universidad de Sevilla. Sevilla : España. PP 7-20.

Canaves, P. Tele-educacion y tele-trabajo. Monografia.com. www. .Publicado 7 dic 1999. Universidad de Belgrano. Argentina

Exploring Tangible Benefits of e-Leaming:Does investment yield interest? JISC InfoNET PublishedApril 2008. Northumbria University. Inglaterra. ISBN: 978-1-86135-349-8.

http://www.jiscinfonet.ac.uk/publications/camel-tangible-benefits.pdf

R. Ruiz et al (2006), "Herramientas Colaborativas". Gaceta de la Universidad Autónoma de Aguascalientes, año. 8, núm. 72, Aguascalientes, México. 